\title{
PHYSICAL CHEMISTRY EDUCATION - THE 2014 THEMED ISSUE OF CHEMISTRY EDUCATION RESEARCH AND PRACTICE
}

\author{
Georgios Tsaparlis \\ Department of Chemistry, University of Ioannina, GR-451 10 Ioannina, Greece. E-mail: \\ gtseper@cc.uoi.gr
}

\section{Odilla E. Finlayson}

School of Chemical Sciences, Dublin City University, Dublin 9, Ireland. E-mail: odilla.finlayson@dcu.ie

\begin{abstract}
The July 2014 issue of the Chemistry Education Research and Practice is dedicated to physical chemistry education. Major sub-themes are: the role of controversies in PC education, quantum chemistry, chemical thermodynamics (including a review of research on the teaching and learning of thermodynamics) and PC textbooks. Topics covered include: the significance of the origin of $\mathrm{PC}$ in connection with the case of electrolyte solution chemistry; the true nature of the hydrogen bond; using the history of science and science education for teaching introductory quantum physics and quantum chemistry; a module for teaching elementary quantum chemistry; undergraduate students' conceptions of enthalpy, enthalpy change and related concepts; particulate level models of adiabatic and isothermal processes; prospective teachers' mental models of vapor pressure; an instrument that can be used to identify students' alternative conceptions regarding thermochemistry concepts; and the organization/ sequencing of the major areas of PC in many PC textbooks.
\end{abstract}

\section{Introduction}

Physical chemistry (PC) is considered as one of the fundamental and essential courses in the undergraduate curricula of all chemistry and many other departments. It is also perceived as a difficult course by students and instructors alike. A number of chemistry and scienceeducation studies have focused on general aspects of teaching and learning PC (Derrick and Derrick, 2002; Hahn and Polik, 2004; Nicoll and Francisco, 2001; Sözbilir, 2004), as well as on students' difficulties of understanding and misconceptions in various areas of PC. For a review see Tsaparlis (2008).

The 2014 special issue of Chemistry Education Research and Practice (CERP) ${ }^{1}$, published in July 2014, is dedicated to physical chemistry education and its multiple facets and aspects - historical, philosophical, psychological, conceptual, contextual, experimental, theoretical, mathematical, computational, phenomenological and molecular - as well as to its various areas, such as classical thermodynamics, electrochemistry, chemical kinetics,

\footnotetext{
${ }^{1}$ Chemistry Education Research and Practice (CERP) is a peer-reviewed electronic-only journal, which is published by the Royal Society of Chemistry, and is free to access, for both publication and to read articles: http://www.rsc.org/cerp. CERP's authors and readers extend to all over the world, while since 2008 the journal is included in the Social Science Citation Index. The latest (2013) impact factor is 1.309, making CERP a leading journal for teachers, researchers, and other practitioners in chemistry education.
} 


\section{IMPLEMENTING INNOVATIONS IN A \\ NON-FORMAL STUDENT LABORATORY CONTEXT}

quantum chemistry, statistical thermodynamics, spectroscopy, etc. Many of these aspects are reflected in this themed issue.

\section{Short review of the contents}

The issue starts with an editorial article ${ }^{2}$ by the themed issue editors (Tsaparlis and Finlayson, 2014), which provides an extended preview of the contributions, and where appropriate highlights common elements between contributions. The editorial concludes with insights into the areas for future research in PC education and a postscript on controversies and disjunctiveness in PC education.

The presentation in the editorial reflects the organization of the papers in the themed issue, and has the following sections: The history of physical chemistry and the role of controversies in education; Quantum chemistry; Thermodynamics; Physical chemistry textbooks; Looking ahead: emerging themes for future research in physical chemistry education.

Three papers deal with old or current controversies in PC and how these can be used for the advancement of PC education. de Berg (2014) considers the significance of the origin of PC as reflected in the ionists vs. hydrationists controversy in connection with the case of electrolyte solution chemistry, and in particular with the data on osmotic pressure, which led to an equation of state for aqueous solutions. Weinhold and Klein (2014) address the understanding of the true nature of hydrogen bonding, based both on quantum chemical calculations and on experimental data, with the aim of contributing to resolving the longstanding controversy between electrostatic 'dipole- dipole' vs. 'partial covalency' descriptions of hydrogen bonding. Finally, the lessons from the history of quantum physics in relation to the ongoing controversy over its interpretations and foundations are considered by Greca and Freire J r. (2014) as a way of improving the teaching of quantum physics and quantum chemistry.

In addition to the two papers by Weinhold and Klein and by Greca and Freire Jr., two further papers deal with educational aspects of quantum chemistry. Dangur, Avargil, Peskin and Dori (2014) developed a module for teaching elementary quantum chemistry, emphasizing interdisciplinary real-life applications and investigated the effect of the module on the visual and textual understanding of quantum mechanical concepts. Barradas-Solas and Sánchez Gómez (2014) examine the omnipresence in textbooks and research literature of graphical and pictorial representations of the so called 'chemical orbitals' as they are used to represent both chemical structures and processes (e.g. reaction mechanisms).

Five papers deal with the teaching and learning of thermodynamics. Bain, Moon, Mack, and Towns (2014) review systematically the literature from different discipline-based education research resources: chemistry, physics, engineering, and undergraduate mathematics education. Nilsson and Niedderer (2014) study undergraduate students'

\footnotetext{
${ }^{2}$ The contents of this paper are based almost entirely on the themed-issue editorial article.
} 
conceptions of enthalpy, its change and related thermochemistry concepts. Making a shift from classical thermodynamics, Hernández, Criswell, Kirk, Sauder, and Rushton (2014) consider a number of issues related to the particulate-level models of adiabatic and isothermal processes in upper-level (advanced undergraduate and beginning graduate) chemistry courses. Tumay (2014) distinguishes between mental models and misconceptions and derives prospective teachers' mental models of vapour pressure. Finally, assessment is the focus of the study by Wren and Barbera (2014), who report on quantitative evidence for the uses and interpretations of data from their thermochemistry concept inventory.

The Tsaparlis paper (2014) examines the organization/ sequencing of the major areas of PC in PC textbooks. As an ultimate research question, the author asks if there is an 'optimum teaching-learning sequence' for undergraduate instruction for the various major areas of PC. According to the author, this is a controversial issue, which cannot be answered solely by the analysis of textbooks, but a wide range of information should be considered.

\subsection{Two further papers}

Two further papers missed the publication date of the themed issue. One paper is now published in CERP (Nyachwaya and Wood, 2014). The authors analyzed a sample of 12 PC textbooks that are commonly used in the United States. They found that symbolic representations were most common, followed by sub-microscopic ones, while macroscopic representations were used least. The other paper will be published in CERP in J anuary 2015 (Yalçınkaya and Boz, 2015). It investigates the effect of case-based instruction on 10th grade students' understanding of gas concepts. Acconding to the findings, case-based instruction was an effective method for overcoming students' alternative conceptions about the gas concepts.

\section{Perspectives for future research in physical chemistry education}

The call for papers for this themed CERP issue included an extended list of indicative topics for contribution. They were as follows:

- The abstract nature of physical chemistry

- Conceptual understanding in the various sub-disciplines of physical chemistry

- Concept learning versus mathematical approach to physical chemistry

- Assessment of physical chemistry - testing for conceptual understanding or

- mathematical manipulation

- Mathematical coverage and mathematical rigour: how much and how far?

- Problem solving related to physical chemistry

- The physical chemistry laboratory

- The physical chemistry curriculum

- The role of textbooks in the teaching of physical chemistry

- The interface of physical chemistry with the other branches of chemistry

- Physical chemistry in context

- Computational chemistry 
- Use of symbolic mathematics engines for data analysis, model building, and problem solving

- Computer simulations and online learning in physical chemistry

- Physical chemistry concepts and topics as part of general chemistry courses at

- second and third level

- Reviews and perspectives (including historical perspectives).

The topics that are covered in the themed issue are shown in italics, while the remaining topics are not represented. Although there had been manuscripts submitted for this themed issue for some of these topics, other topics lacked submissions. Finally, key areas for future education research in the special domain of physical chemistry are outlined in the editorial article. This may be a useful starting point for those researchers interested in emerging themes for future research in physical chemistry education. 


\section{References}

Avargil D. S., Peskin U. and J udy Dori Y. J. (2014). Learning quantum chemistry via a visualconceptual approach: students' bidirectional textual and visual understanding. Chemistry Education Research and Practice, 15, 297-310

Bain K., Moon A., Mack M. R. and Towns M. H. (2014). A review of research on the teaching and learning of thermodynamics at the university level. Chemistry Education Research and Practice, 15, 320-335

Barradas-Solas F. and Sánchez Gómez P. J . (2014). Orbitals in chemical education. An analysis through their graphical representations. Chemistry Education Research and Practice, 15, 311319

de Berg K. C. (2014). The significance of the origin of physical chemistry for physical chemistry education: the case of electrolyte solution chemistry. Chemistry Education Research and Practice, 15, 266-275

Derrick M. E. and Derrick F. W. (2002). Predictors of success in physical chemistry. J ournal of Chemical Education, 79, 1013- 1016.

Greca I. M. and Freire Jr. O. (2014). Teaching introductory quantum physics and chemistry: caveats from the history of science and science teaching to the training of modern chemists. Chemistry Education Research and Practice, 15, 286-296

Hahn K. E. and Polik W. F. (2004). Factors influencing success in physical chemistry. J ournal of Chemical Education, 81, 567- 572.

Hernández G. E., Criswell B. A., Kirk N. J ., Sauder D. G., and Rushton G. T. (2014). Pushing for particulate level models of adiabatic and isothermal processes in upper-level chemistry courses: a qualitative study. Chemistry Education Research and Practice, 15, 354-365

Nicoll G. and Francisco J . S. (2001). An investigation of the factors influencing student performance in physical chemistry. J ournal of Chemical Education, 78, 99- 102.

Nilsson T. and Hans Niedderer H. (2014). Undergraduate students' conceptions of enthalpy, enthalpy change and related concepts. Chemistry Education Research and Practice, 15, 336-353

Nyachwaya J. M. and Wood N. B. (2014). Evaluation of chemical representations in physical chemistry textbooks. Chemistry Education Research and Practice, 15, 720-728

Sözbilir M. (2004). What makes physical chemistry difficult? Perceptions of Turkish chemistry undergraduates and lecturers. J ournal of Chemical Education, 81, 573- 578.

Tsaparlis G., (2008). Teaching and learning physical chemistry - review of educational research. In Ellison M. D. and Schoolcraft T. A. (eds.), Advances in teaching physical chemistry, Washington, DC: American Chemical Society/ Oxford University Press, pp. 75- 112.

Tsaparlis G. (2014). The logical and psychological structure of physical chemistry and its relevance to the organization/ sequencing of the major areas covered in physical chemistry textbooks. Chemistry Education Research and Practice, 15, 391-401

Tsaparlis G. and Finlayson O. E. (2014). Physical chemistry education: its multiple facets and aspects (Editorial). Chemistry Education Research and Practice, 15, 257-265

Tümay H. (2014). Prospective chemistry teachers' mental models of vapor pressure. Chemistry Education Research and Practice, 15, 366-379

Weinhold F. and Klein R. A. What is a hydrogen bond? Resonance covalency in the supramolecular domain. Chemistry Education Research and Practice, 15, 276-285.

Wren D. and Barbera J . (2014). Psychometric analysis of the thermochemistry concept inventory. Chemistry Education Research and Practice, 15, 380-390.

Yalçınkaya E. and Boz Y. (2015). The effect of case-based instruction on 10th grade students' understanding of gas concepts. Chemistry Education Research and Practice, Advance Article. 